Article

\title{
Single-Dose Toxicity of Individual and Combined Sterigmatocystin and 5-Methoxysterigmatocistin in Rat Lungs
}

\author{
Daniela Jakšić $^{1}{ }^{\circledR}$, Ida Ćurtović ${ }^{1}$, Domagoj Kifer ${ }^{1}$, Dubravka Rašić $^{2}{ }^{\circledR}$, Nevenka Kopjar ${ }^{2}$, \\ Vedran Micek $^{2}$, Maja Peraica ${ }^{2}$ and Maja Šegvić Klarić ${ }^{1, * \mathbb{D}}$ \\ 1 Faculty of Pharmacy and Biochemistry, University of Zagreb, 10000 Zagreb, Croatia; \\ djaksic@pharma.unizg.hr (D.J.); icurtovic@student.pharma.unizg.hr (I.Ć.); dkifer@pharma.unizg.hr (D.K.) \\ 2 Institute for Medical Research and Occupational Health, 10000 Zagreb, Croatia; rasic@imi.hr (D.R.); \\ nkopjar@imi.hr (N.K.); vmicek@imi.hr (V.M.); mperaica@imi.hr (M.P.) \\ * Correspondence: msegvic@pharma.unizg.hr
}

Received: 30 October 2020; Accepted: 20 November 2020; Published: 23 November 2020

\begin{abstract}
Sterigmatocystin (STC) and 5-methoxysterigmatocystin (5-M-STC) are mycotoxins produced by common damp indoor Aspergilli series Versicolores. Since both STC and 5-M-STC were found in the dust of indoor occupational and living areas, their occupants may be exposed to these mycotoxins, primarily by inhalation. Thus, STC and 5-M-STC were intratracheally instilled in male Wistar rats using doses $(0.3 \mathrm{mg} \mathrm{STC} / \mathrm{kg}$ of lung weight (l.w.); $3.6 \mathrm{mg}$ 5-M-STC/ $\mathrm{kg}$ l.w.; toxin combination $0.3+3.6 \mathrm{mg} / \mathrm{kg}$ l.w.) that corresponded to concentrations detected in the dust of damp indoor areas in order to explore cytotoxicity, vascular permeability, immunomodulation and genotoxicity. Single mycotoxins and their combinations insignificantly altered lactate-dehydrogenase activity, albumin, interleukin- 6 , tumor necrosis factor- $\alpha$ and chemokine macrophage inflammatory protein- $1 \alpha$ concentrations, as measured by ELISA in bronchioalveolar lavage fluid upon $24 \mathrm{~h}$ of treatment. In an alkaline comet assay, both mycotoxins provoked a similar intensity of DNA damage in rat lungs, while in a neutral comet assay, only 5-M-STC evoked significant DNA damage. Hence, naturally occurring concentrations of individual STC may induce DNA damage in rat lungs, in which single DNA strand breaks prevail, while 5-M-STC was more responsible for double-strand breaks. In both versions of the comet assay treatment with STC + 5-M-STC, less DNA damage intensity occurred compared to single mycotoxin treatment, suggesting an antagonistic genotoxic action.
\end{abstract}

Keywords: Aspergilli series Versicolores; sterigmatocystin; 5-methoxysterigmatocystin; intratarcheal instillation; genotoxicity; pro-inflammatory cytokines

Key Contribution: STC and 5-M-STC alone and their combination, applied in naturally occurring concentrations detected in the dust of damp indoor areas, induced significant DNA damage in the lungs of Wistar rats.

\section{Introduction}

Sterigmatocystin (STC) is one of the most commonly occurring polyketide mycotoxins in damp occupational and indoor living areas [1-3], principally produced by Aspergillus section Nidulantes series Versicolores that can be found in indoor damp occupational and living environments [4]. Recent studies have shown that among Aspergilli series Versicolores, the most frequent contributors of STC in dust of occupational and/or residential environments were the species $A$. jensenii and $A$. creber, followed by A. protuberus, A. puulaauensis, A. tennesseensis, A. venenatus, A. amoenus, A. griseoaurantiacus, A. fructus 
and A. pepii [5-7]. 5-Methoxysterigmatocystin (5-M-STC) is produced in association with STC by some Aspergilli series Versicolores, sometimes at higher levels than STC [8].

STC is a precursor in aflatoxin biosynthesis and is therefore structurally related to aflatoxins [9]. Similarly to aflatoxin, STC is activated by the liver cytochrome P450 (CYP450) system with reactive epoxide that forms DNA adducts with guanine, and this is considered the underlying mechanism of STC genotoxicity [9]. STC-induced tumors, including hepatocellular carcinomas, hemangiosarcomas of the liver and pulmonary adenomas, resulted in its classification as a 2B carcinogen (possible human carcinogen) by the International Agency for Research on Cancer (IARC) $[9,10]$. STC induces lung adenocarcinoma in mice, genotoxicity and $\mathrm{G}_{2}$ cell cycle arrest in human immortalized bronchial epithelial BEAS-2B cells, human lung adenocarcinoma A549 cells and human esophageal epithelial Het-1A cells, and it is more cytotoxic than aflatoxin to A549 cells [11-13]. Intratracheally instilled STC in white Swiss Webster mice modulated inflammation-associated genes after $4 \mathrm{~h}$ of treatment, while after $12 \mathrm{~h}$ of instillation, mucus production and inflammation of the bronchiolar and alveolar epithelium and alveolar edema appeared [14].

The toxic properties of 5-M-STC have been poorly investigated to date. In terms of toxicity, a TA100 Salmonella typhimurium mutagenicity assay showed that 5-M-STC is mutagenic in the presence of metabolic activation [15] and is cytotoxic and genotoxic to A549 cells [16,17]. Both STC and 5-M-STC are detoxified through conjugation in primary tracheal epithelial cells. While STC is activated by CYP enzymes producing reactive epoxide, no such metabolite was detected with 5-M-STC [8,18].

In our recent study [6] in damp dwellings, 75 fungal metabolites were detected in dust samples and STC and 5-M-STC were among the dominant mycotoxins. The highest concentration of STC was $0.59 \mu \mathrm{g} / \mathrm{g}$, while 5-MET-STC was recovered at a maximum level of $7.70 \mu \mathrm{g} / \mathrm{g}$. Considering the reported frequent occurrence of STC- and 5-M-STC-producing Aspergilli series Versicolores [2,7,19], these two mycotoxins could be frequently expected in indoor damp occupational and living environments. Taking into account the maximal concentrations of STC $(0.59 \mu \mathrm{g} / \mathrm{g})$ and $5-\mathrm{M}-\mathrm{STC}(7.70 \mu \mathrm{g} / \mathrm{g})$ found in dust, exploring the cytotoxic, inflammatory and genotoxic effects of STC and 5-M-STC alone, as well as their combination, in the lungs of male Wistar rats upon a single intratracheal instillation of mycotoxins was justified. Concentrations used for animal treatment were calculated according to following data related to human respiratory exposure to particulate matter $\left(\mathrm{PM}_{2.5}\right)$ : (i) average daily inhalation of adults is $10-12 \mathrm{~m}^{3}$ and the average concentration of $\mathrm{PM}_{2.5}$ could be up to $54 \mu \mathrm{g} / \mathrm{m}^{3}$ [20,21]; (ii) by multiplying these values, we can assume that the average daily inhaled $\mathrm{PM}_{2.5}$ could be up to $648 \mu \mathrm{g}$; (iii) thus, the daily inhaled STC and 5-M-STC would be $0.4 \mu \mathrm{g}$ and $5 \mu \mathrm{g}$, respectively. These levels of STC and 5-M-STC were used in the experiment.

\section{Results}

Bronchioalveolar lavage fluid (BALF) was used as a sample for measuring (ELISA) lactate dehydrogenase (LDH) activity as an indicator of cytotoxicity, albumin as an indicator of vascular permeability and the cytokines interleukin-6 (IL-6), tumor necrosis factor- $\alpha$ (TNF- $\alpha$ ) and chemokine macrophage inflammatory protein-1 (MIP-1 $\alpha)$ as indicators of inflammation. Homogenized rat lungs were used as samples for measuring the levels of DNA damage by alkaline and neutral comet assays.

\subsection{LDH Activity}

Cytotoxicity expressed as LDH activity levels measured in BALF upon $24 \mathrm{~h}$ of intratracheal instillation of mycotoxins is presented in Figure 1. STC and 5-M-STC alone and their combinations increased LDH activity in treated rats at similar levels, but without significant differences compared to control rats $(p>0.05)$. 


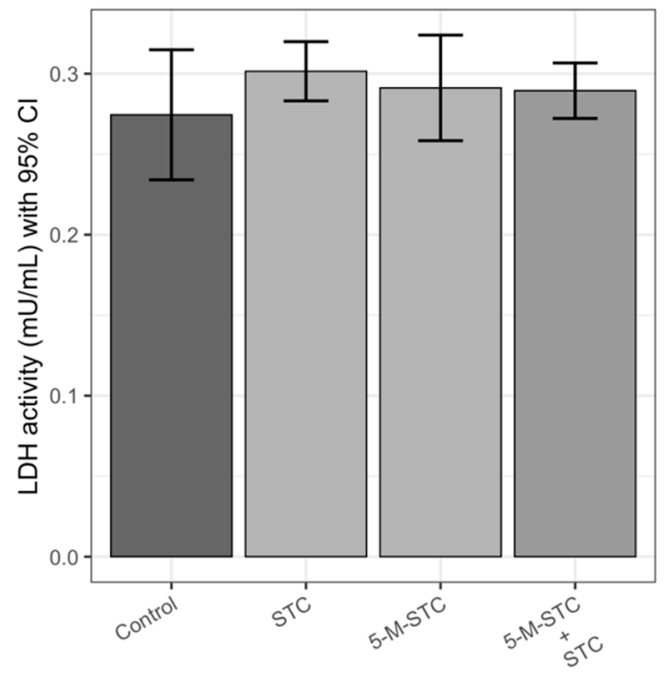

Figure 1. Lactate dehydrogenase (LDH) activity in bronchioalveolar lavage fluid (BALF) of Wistar rats upon $24 \mathrm{~h}$ of intratracheal instillation of mycotoxins. Each experimental group comprised six animals. Bar height reflects mean LDH activity of each group in $\mathrm{nmol} / \mathrm{mL} / \mathrm{min}(\mathrm{mU} / \mathrm{mL})$, error bars present upper and lower limit of 95\% confidence interval (CI). Abbreviations: STC—-sterigmatocystin, 5-M-STC-5-metoxysterigmatocysin. Control rats were treated with 0.3\% DMSO.

\subsection{Albumin}

Albumin concentration in BALF was measured as a nonspecific indicator of vascular permeability. The increase in albumin concentration was detected in rats instilled with 5-M-STC and the combination STC + 5-M-STC, but these changes were not associated with a significant difference with respect to albumin concentration in control animals $(p>0.05)$ (Figure 2).

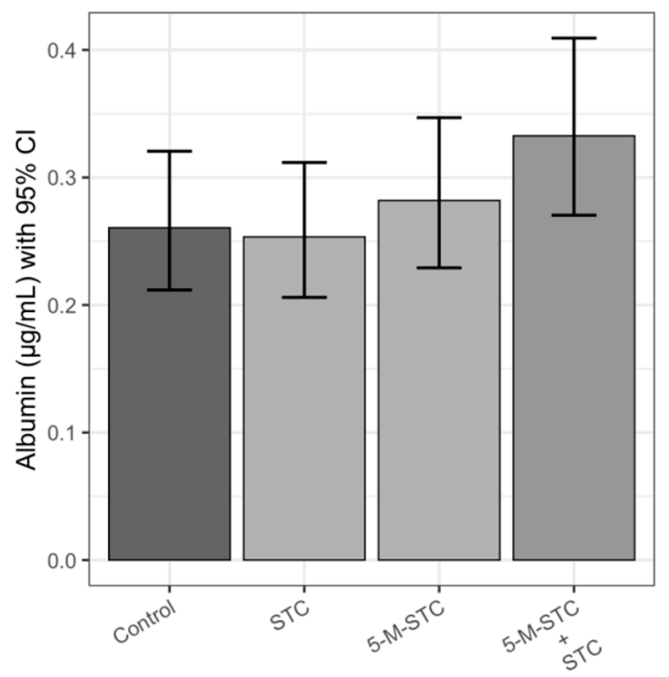

Figure 2. Albumin concentrations in BALF of Wistar rats upon $24 \mathrm{~h}$ of intratracheal instillation of mycotoxins. Each experimental group comprised six animals. Bar height reflects mean albumin concentration of each group in $\mu \mathrm{g} / \mathrm{mL}$, error bars present upper and lower limit of $95 \%$ confidence interval (CI). Abbreviations: STC—sterigmatocystin, 5-M-STC-5-metoxysterigmatocysin. Control rats were treated with $0.3 \%$ DMSO.

\subsection{Pro-Inflammatory Cytokines and Chemokine}

The concentrations of pro-inflammatory cytokines TNF- $\alpha$ and IL- 6 as well as the chemokine MIP- $1 \alpha$ are presented in Figure 3. Single mycotoxins insignificantly decreased TNF- $\alpha$ and IL- 6 with respect to the control $(p>0.05)$, while the combination of STC and 5-M-STC returned the concentrations 
of cytokines to control values. Opposite to cytokines, MIP- $1 \alpha$ was more decreased in rats treated with the mycotoxin combination $(p>0.05)$, while in rats instilled with single toxins, the levels of MIP- $1 \alpha$ were more similar to control values.

A

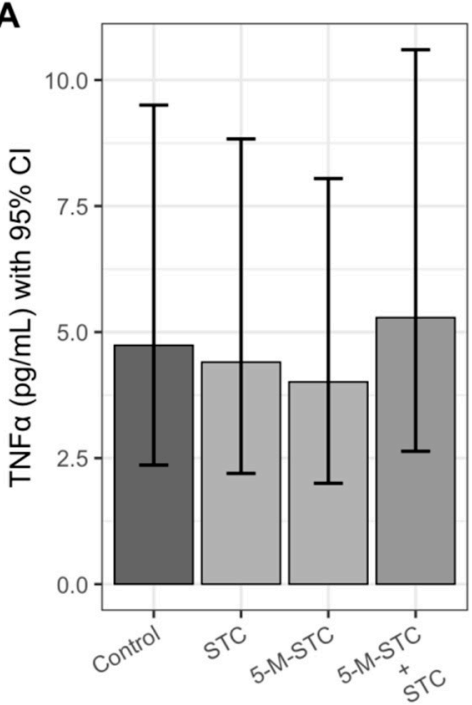

B

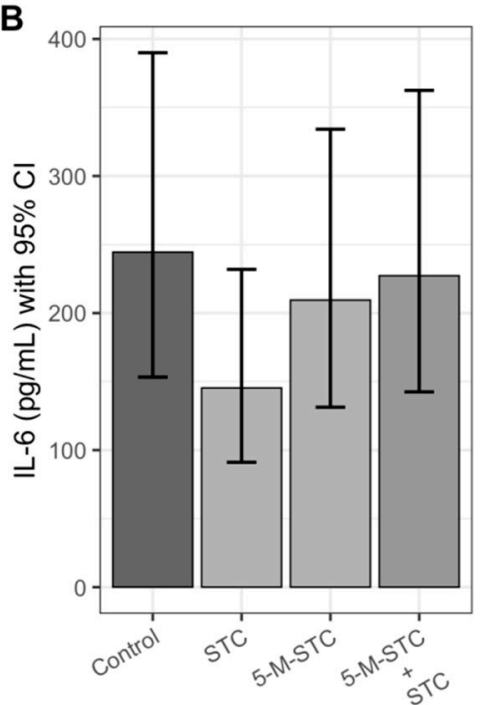

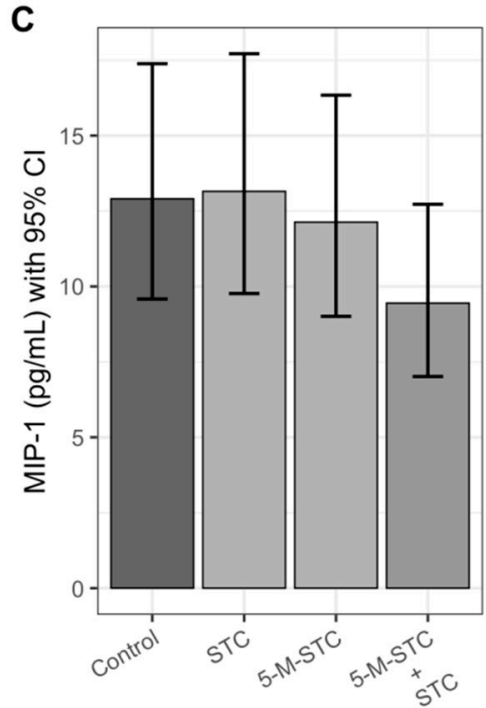

Figure 3. Cytokines (TNF- $\alpha$ and IL-6) and chemokine (MIP- $1 \alpha$ ) concentration in BALF of Wistar rats upon $24 \mathrm{~h}$ of intratracheal instillation of mycotoxins. Each experimental group comprised six animals. Mean concentrations in pg/mL of cytokines (A) TNF- $\alpha$, (B) IL- 6 and chemokine (C) MIP- $1 \alpha$ are presented with bar height. Error bars present $95 \%$ confidence interval (CI). Abbreviations: STC—-sterigmatocystin, 5-M-STC-5-metoxysterigmatocysin. Control rats were treated with $0.3 \%$ DMSO.

\subsection{DNA Damage Measured by Alkaline and Neutral Comet Assays}

The results of the genotoxic effects of STC and 5-M-STC measured by alkaline and neutral comet tests are shown as tail length (TL) and tail intensity (TI) in Figures 4 and 5.
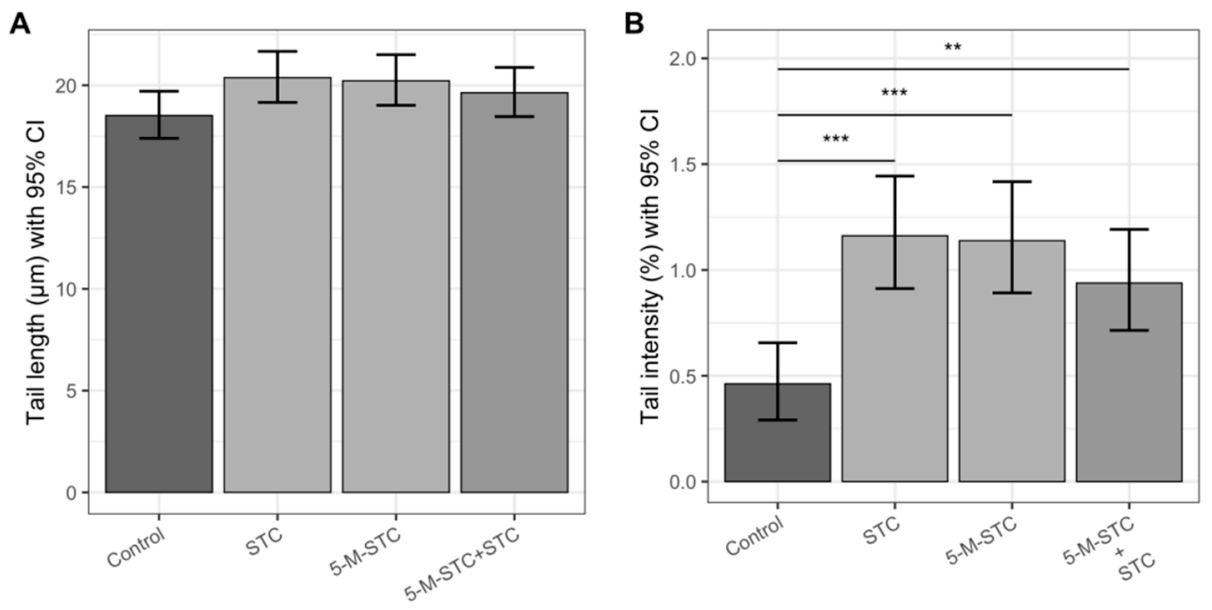

Figure 4. Genotoxic effects obtained by alkaline comet assay in the lungs of Wistar rats following $24 \mathrm{~h}$ of intratracheal instillation of mycotoxins. Each experimental group comprised six animals. (A) Mean TLs in $\mu \mathrm{m}$ measured in the alkaline comet assay are presented with bar heights, while error bars reflect upper and lower limits of the 95\% confidence interval (CI). (B) Mean Tis in percentage units measured in the alkaline comet assay are presented with bar heights, while error bars reflect upper and lower limits of the $95 \%$ confidence interval (CI). Statistically significant differences between the groups below at the ends of each line are emphasized with asterisks encoding $p$ values: ${ }^{* * *}<0.001 \leq^{* *}<0.01 \leq$. Abbreviations: STC—sterigmatocystin, 5-M-STC—5-metoxysterigmatocysin. Control rats were treated with $0.3 \%$ DMSO. 
A

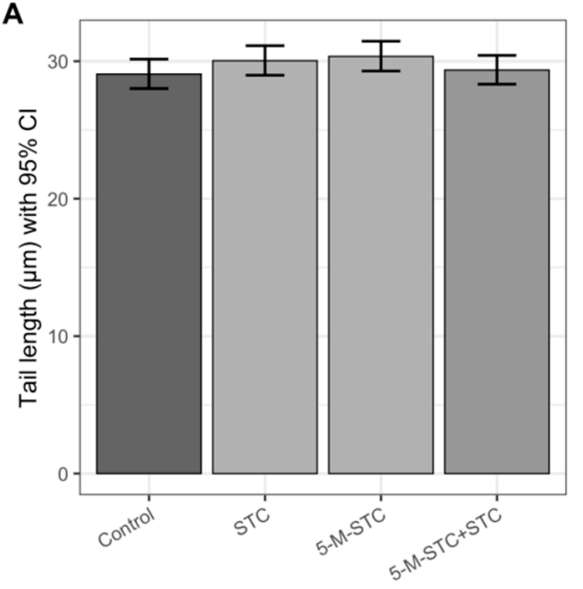

B

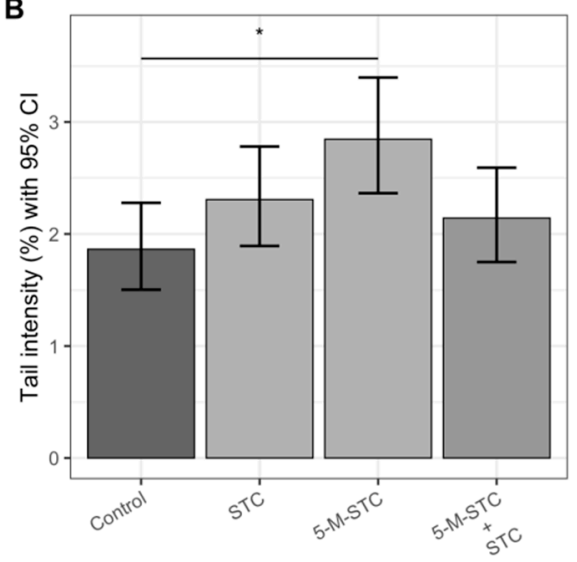

Figure 5. Genotoxic effects obtained by neutral comet assay in the lungs of Wistar rats following $24 \mathrm{~h}$ of intratracheal instillation of mycotoxins. Each experimental group comprised six animals. (A) Mean TLs in $\mu \mathrm{m}$ measured in the neutral comet assay are presented with bar heights, while error bars reflect upper and lower limits of the 95\% confidence interval (CI). (B) Mean TIs in percentage units measured in the neutral comet assay are presented with bar heights, while error bars reflect upper and lower limits of the $95 \%$ confidence interval (CI). Statistically significant differences between the groups below at the ends of each line are emphasized with asterisks encoding $p$ value $*<0.05$. Abbreviations: STC—sterigmatocystin, 5-M-STC—5-metoxysterigmatocysin.

Both versions of the comet assay revealed no significant increase in TL (Figures 4A and 5A) in the treatment groups compared to the control. However, the alkaline comet assay showed that the levels of DNA damage, represented by TI, were significantly higher in rats instilled with individual mycotoxins and their combination than in control rats $(p<0.001$ and $p<0.01$, respectively). The two-toxin combination provoked lower TI than the individual toxins, but the difference was not statistically significant.

In the neutral comet assay (Figure 5B), a significant increase in TI was observed upon treatment with 5-M-STC alone compared to the control $(p<0.05)$. Although STC and the combination of STC +5 -M-STC caused slightly greater DNA damage compared to the control, the TI increase was not statistically significant. Treatment of animals with STC and the combination of STC + 5-M-STC evoked a lower TI compared to 5-M-STC administered alone, but also did not show a significant difference.

\section{Discussion}

Our recent unpublished results revealed that STC (85\%), along with its derivative 5-M-STC (70\%), was among the dominant fungal metabolites in the dust of damp dwellings during a post-flood period, linked to the presence of Aspergilli series Versicolores, capable of producing both mycotoxins in vitro. That study revealed that the majority of indoor airborne and dustborne isolates of $A$. jensenii, A. creber, A. puulaauensis, $A$. tennesseensis and $A$. venenatus were capable of producing both STC and its derivative 5-M-STC; the isolates produced two to five times more 5-M-STC than STC. Data on 5-M-STC-producing Aspergilli, as well as the occurrence of this mycotoxin in dust samples of occupational and indoor living areas are scarce. Very few studies reported the occurrence of 5-M-STC in indoor environments in relation to materials contaminated by $A$. versicolor $[22,23]$ but, more recently, the presence of both 5-M-STC and STC in library dust was primarily attributed to $A$. jensenii and A. creber [19], which was supported by our results. In library dust, both STC and 5-M-STC were present at similar mean concentrations, ranging from 2.1 to $17.4 \mu \mathrm{g} / \mathrm{kg}$ and 4.8 and $27 \mu \mathrm{g} / \mathrm{kg}$, respectively [19]. In our study [6], the average concentration of 5-M-STC $(215 \mu \mathrm{g} / \mathrm{kg})$ in indoor dust was eight times higher than the concentration of STC $(28 \mu \mathrm{g} / \mathrm{kg})$, suggesting that Aspergilli could produce significantly larger amounts of 5-M-STC than STC when higher water activity is available in the substrate, which is in line with limited reports in artificially inoculated materials $[8,23]$. Furthermore, in occupational environments, 
such as a grain mill, relatively high STC levels $(0.06-2.35 \mu \mathrm{g} / \mathrm{g})$ were detected in dust [7], suggesting that its derivative 5-M-STC might also be present in large amounts. Thus, occupants in specific working environments heavily contaminated with organic dust (e.g., grain storage, grain elevators and mills) may be exposed to high levels of both STC and 5-M-STC, primarily via inhalation.

Having in mind the maximum concentrations of mycotoxins detected in the dust of damp indoor areas in post-flood periods, one single dose per lung weight (l.w.) of STC $(0.3 \mathrm{mg} / \mathrm{kg} \mathrm{l.w.})$ and 5-M-STC $(3.6 \mathrm{mg} / \mathrm{kg}$ l.w.), as well as their combination $(0.3+3.6 \mathrm{mg} / \mathrm{kg}$ l.w.), were intratracheally instilled in male Wistar rats. Several toxicity studies in rodents, including mice and rats, available in the literature were done with STC alone $[9,12,24]$, while there are limited results on 5-M-STC in vitro $[16,17,25]$ and no data on its toxicity in vivo. This study shows that naturally occurring concentrations of STC and 5-M-STC alone, as well as their combination, insignificantly increase LDH activity and vascular permeability in rat lungs and we can only speculate that an increase in the dose would produce significant alterations.

As is well known, TNF- $\alpha$ and IL- 6 are pro-inflammatory cytokines produced by lymphocytes, monocytes and epithelial cells [26]. TNF- $\alpha$ is an endogenous pyrogen and immunoregulatory cytokine responsible for the production of interleukins, including IL-6, which leads to the activation of T cells and the differentiation of B cells, as well as immunoglobulin secretion $[27,28]$. The chemokine MIP- $1 \alpha$ plays an important role in the inflammatory process by promoting the recruitment of neutrophils, macrophages and lymphocytes to the site of inflammation [29]. Both TNF- $\alpha$ and IL- 6 were insignificantly decreased by STC and 5-M-STC alone in the BALF of rat lungs, and returned to control values following treatment with their combination. In mice, an interperitoneal injection of a 10 times higher dose of STC $(3 \mathrm{mg} / \mathrm{kg}$ ) significantly downregulated the expression of TNF- $\alpha$ and IL-6 in intraperitoneal macrophages, together with a decrease in both cytokines in serum [30]. On the other hand, in mice intratracheally instilled with STC, at half the dose $(0.138 \mathrm{mg} / \mathrm{kg}$ l.w.) in the present study, it provoked significant inflammation, observed as the infiltration of leukocytes in bronchi, swollen macrophages in alveolar spaces and the upregulated expression of TNF- $\alpha$ and the chemokine MIP-2 [14]. Altogether, this suggests that: (i) STC immunomodulatory effects depend on the applied dose; (ii) in naturally occurring concentrations detected in damp dwellings, STC and 5-M-STC, as structurally similar toxins, may have negative immunomodulatory effects when present alone; (iii) since treatment with STC + 5-M-STC returned pro-inflammatory cytokines and chemokine to control values, an immunomodulatory antagonism within a toxin combination may be expected. Additionally, STC induced an insignificant increase in TNF- $\alpha$ in human THP-1-like macrophages, while co-exposure with $\beta$-glucan resulted in a synergistically increased expression of several inflammation-related genes [31], suggesting that mycotoxins may exhibit pro-inflammatory synergistic action with structures of the fungal cell wall that are expected in dust of occupational and indoor living areas.

Although the STC and 5-M-STC doses used in the present study did not exert significant cytotoxicity and immunomodulation in rat lungs, significant genotoxic action was obtained by two types of comet assay. The principle of the comet assay is based on DNA damage, such as strand breaks, resulting in the extension of DNA loops from lysed nuclei, which form comet-like tails; after alkaline electrophoresis, single-strand breaks dominate, but double-strand breaks are also detected in tails, while neutral electrophoresis indicates the domination of double-strand breaks [32]. Relative TI is the most useful parameter of the comet assay because the tail increases in intensity, but not in length, as DNA damage increases, while TL increases only when tails first become established at a relatively low damage level [33]. Looking at TI, in the alkaline comet assay, both STC and 5-M-STC provoked a similar intensity of DNA damage, although STC was applied at an approximately 10 times lower dose than 5-M-STC, while in the neutral comet assay version, only 5-M-STC evoked significant DNA damage. These results suggest that naturally occurring concentrations of STC alone may induce DNA damage in rat lungs, in which single DNA strand breaks prevail, while 5-M-STC is more responsible for double-strand breaks. In both versions of the comet assay, treatment with the toxin combination resulted in lower TI compared to single mycotoxin treatment, suggesting the antagonistic genotoxic action of STC and 5-M-STC. The present study is the first to report on the genotoxic action of 5-M-STC in vivo, as well as 
the genotoxic action of the STC + 5-M-STC combination. The nature of DNA strand breaks induced by STC has not been elucidated yet. In porcine primary tracheal epithelial cells treated with STC $(50 \mu \mathrm{M})$, CYP enzymes produced a reactive STC metabolite [18], which may interact with DNA, leading to DNA single-strand breaks. On the other hand, a recent study revealed that STC at concentrations between 5 and $10 \mu \mathrm{M}$ possesses unique aggregation properties in water, yielding a strong and specific circular dichroism spectrum [34]. Data showed that STC non-covalently interacts with DNA, most probably by intercalation between base pairs, which may result in DNA double-strand breaks [34]. We can only speculate whether both mechanisms may be in action, depending on the bioavailable concentration of STC and CYP activity. In porcine primary tracheal epithelial cells, 5-M-STC applied at $1 \mu \mathrm{M}$ was unable to produce CYP-related reactive metabolites [8]. Taking into account the neutral comet assay results obtained in the present study, as well as the structural similarities of 5-M-STC and STC, we may speculate that the intercalation of 5-M-STC yielded a significant amount of DNA double-strand breaks. This hypothesis should be further explored. In human adenocarcinoma A549 cells, both mycotoxins in single treatments at sub-cytotoxic concentrations induced significant reversible and irreversible DNA damage, as measured by comet and micronucleus tests [16]. The mechanism of STC genotoxicity in pulmonary cell lines (A549 and BEAS-2B cells) has been linked to cell cycle arrest in $G_{2} / S$ and $G_{2} / M$, in which STC altered the expression of the regulatory protein cyclin and cyclin-dependent kinases [35]. This mechanism of DNA damage might be worth exploring in vivo by applying naturally occurring concentrations of STC and 5-M-STC, as well as their combinations.

In conclusion, STC and 5-M-STC alone and their combination, applied at naturally occurring concentrations detected in damp indoor areas, evoked significant DNA damage, but insignificant cytotoxicity, alterations in vascular permeability and immunomodulation in the lungs of Wistar rats. Changes in the measured parameters after treatment with the STC and 5-M-STC combination suggest their antagonistic interaction. The underlying mechanisms of genotoxicity of single and combined STC and 5-M-STC should be further explored.

\section{Materials and Methods}

\subsection{Experimental Design and BALF Sampling}

Adult male Wistar rats (12 weeks old, 300-400 g of body weight (b.w.), mean $=343$; mean of lung weight (l.w.) $=1.382 \mathrm{~g}$ ) were kept in macrolon cages at a controlled room temperature and day/night cycles $\left(22{ }^{\circ} \mathrm{C}, 12 \mathrm{~h}\right.$, respectively). Before and during the experiment, animals had free access to standard pelleted food (4RF21 from Mucedola, Settimo Milanese, Italy) and tap water. The experiment was approved by the Ethics Committee of the Institute for Medical Research and Occupational Health in accordance with the European Communities Council Directive of 22 September 2010 (2010/63/EU). Animals ( $N=24)$ were randomly divided into four groups ( $N=6$ in each group) as follows: control (DMSO + PBS); STC; 5-M-STC; and STC + 5-M-STC. Stock solutions of toxins were prepared in DMSO and then diluted to working solutions with PBS. Animals were treated with a single dose of STC $(0.4 \mu \mathrm{g})$ and 5-M-STC $(5 \mu \mathrm{g})$, as well as their combination $(0.4+5 \mu \mathrm{g})$ in DMSO/PBS $(\mathrm{V}=300 \mu \mathrm{L})$, by intratracheal instillation of $300 \mu \mathrm{L}$ between $8 \mathrm{a} . \mathrm{m}$. and 9 a.m. According to the mean lung weight (l.w.) of rats $(1.382 \mathrm{~g})$, doses of toxins were $0.3 \mathrm{mg} \mathrm{STC} / \mathrm{kg}$ l.w. and $3.6 \mathrm{mg} 5-\mathrm{M}-\mathrm{STC} / \mathrm{kg}$ 1.w. Before instillation, animals were lightly anesthetized with isoflurane (Piramal Enterprises LTD, Mumbai, India). Animals were held by hand in the upright position after instillation until awakening, before being placed back in their cages. Animals were sacrificed after $24 \mathrm{~h}$ under general anesthesia by Narketan ( $80 \mathrm{mg} / \mathrm{kg}$ body mass (b.m.) and Xylapan (12 mg/kg b.m., i.p.). Lungs were lavaged with ice-cold PBS in $2 \times 5 \mathrm{~mL}$ and BALF was pulled and centrifuged at $650 \mathrm{G}$ and $4{ }^{\circ} \mathrm{C}$ for $10 \mathrm{~min}$. BALF and lungs were frozen at $-80^{\circ} \mathrm{C}$ until analysis. 


\subsection{LDH Activity Analysis}

The measurement of LDH activity in BALF was performed in 96-wellplates using an LDH Assay Kit (Abcam, Cambridge, UK) on a Tecan Infinite M200PRO plate reader (Tecan Austria GmbH, Grodig, Austria). LDH reduces NAD to NADH, which interacts with a specific probe to produce a color. A standard calibration curve was prepared using NADH standard concentrations of $0-12.5 \mathrm{nmol} / \mathrm{well}$. According to the LDH Assay Kit to $50 \mu \mathrm{L}$ of standard or sample, $50 \mu \mathrm{L}$ of reaction mix were added, mixed, incubated for three hours and measured in kinetic mode at $450 \mathrm{~nm}$, every 2-3 min for $60 \mathrm{~min}$ at $37^{\circ} \mathrm{C}$, protected from light. Absorbance was corrected by subtracting the mean absorbance of the blank from all standards and sample readings. LDH activity was calculated as a concentration of NADH generated by LDH during the reaction time in the volume added to the reaction well.

\subsection{Albumin Analysis}

The measurement of albumin in BALF was performed in 96-well plates using an Abcam Albumin Assay Kit (Abcam, Cambridge, UK) on the Tecan Infinite M200PRO plate reader (Tecan Austria GmbH, Grodig, Austria). The assay is based on the selective interaction between bromcresol green (BCG) and albumin, forming a chromophore that can be detected spectrophotometrically. The signal is directly proportional to the amount present in the serum. A standard calibration curve was prepared using bovine serum albumin (BSA) standard concentrations of $0-75 \mu \mathrm{g} / \mathrm{well}$. All samples were measured in duplicate. To $50 \mu \mathrm{L}$ of undiluted serum, $100 \mu \mathrm{L}$ of diluted BCG were added and plates were incubated at $25^{\circ} \mathrm{C}$ for $20 \mathrm{~min}$, protected from light. Absorbance was measured at $620 \mathrm{~nm}$. The mean value of the absorbance of the blank was subtracted from all standards, samples and control readings. The concentration of albumin, in $\mu \mathrm{g} / \mathrm{mL}$, was calculated from the calibration curve of standards.

\subsection{Cytokines and Chemokine Analysis}

An enzyme-linked immunosorbent assay (ELISA) was employed to measure the levels $(\mathrm{pg} / \mathrm{mL})$ of the pro-inflammatory cytokines interleukin-6 (IL-6) and tumor necrosis factor alpha (TNF- $\alpha$ ), as well as a chemotactic cytokine, MIP- $1 \alpha$, in BALF. The assays were performed using Rat SimpleStep ELISA ${ }^{\circledR}$ kits for IL-6 (ab234570, Abcam, Cambridge, UK), TNF- $\alpha$ (ab46070, Abcam, Cambridge, UK) and MIP-1 $\alpha$ (ab213916, Abcam, Cambridge, UK), following the instructions provided by the manufacturer. To optimize the dilutions of BALF, pilot runs were conducted and a 1:1 dilution was used in all assays. Concentrations of the target proteins IL-6, TNF- $\alpha$ and MIP- $1 \alpha$ in the samples were calculated from a standard curve created by plotting the average blank control-subtracted absorbance value for each standard concentration (y-axis) against the target protein concentration (x-axis) of the standard. Concentrations of the standards ranged from $62.5-4000 \mathrm{pg} / \mathrm{mL}$ for IL-6, $15.625-500 \mathrm{pg} / \mathrm{mL}$ for TNF- $\alpha$ and $7.8-500 \mathrm{pg} / \mathrm{mL}$ for MIP- $1 \alpha$. To optimize the dilutions of BALF, pilot runs were conducted and a 1:1 dilution was used in all assays. The samples and standards were processed in duplicate and absorbanceswere measured at a $450 \mathrm{~nm}$ wavelength using a microplate reader (PerkinElmer VictorX3, Waltham, MA, USA).

\subsection{Alkaline and Neutral Comet Assay}

Comet assays were performed on the lung samples in accordance with previous protocols [36-38]. All of the chemicals used in both comet assays were obtained from Sigma Chemical Company (Sigma-Aldrich, Munich, Germany). Normal melting point (NMP) agarose $0.6 \%$ was layered on slides precoated with $1 \%$ NMP agarose. Suspensions of lung cells ( $\mathrm{V}=10 \mu \mathrm{L}$ per slide) were mixed with $0.5 \%$ low-melting point (LMP) agarose, placed on slides and covered with a top layer of $0.5 \%$ LMP agarose. After solidification, microgels were immersed in a freshly prepared lysis solution $(\mathrm{pH} 10.0 ; 100 \mathrm{mmol} / \mathrm{L}$ $\mathrm{Na}_{2}$ EDTA, $2.5 \mathrm{~mol} / \mathrm{L} \mathrm{NaCl}, 1 \% \mathrm{Na}$ lauroylsarcosinate, $10 \mathrm{mmol} / \mathrm{L} \mathrm{Tris}-\mathrm{HCl}, 10 \%$ DMSO and 1\% Triton $\mathrm{X}-100$ ) and stored overnight at $4{ }^{\circ} \mathrm{C}$. Upon incubation, in the alkaline version of the comet assay, slides were subjected to $15 \mathrm{~min}$ of denaturation $\left(1.5 \mathrm{~mol} / \mathrm{L} \mathrm{NaCl}, 1 \mathrm{mmol} / \mathrm{L} \mathrm{Na}{ }_{2} E D T A, p H ~ 12.1\right)$, 
followed by $20 \mathrm{~min}$ of electrophoresis using the same buffer composition at $0.7 \mathrm{~V} / \mathrm{cm}, 300 \mathrm{~mA}$. In the neutral comet assay, slides were denatured in buffer $(300 \mathrm{mmol} / \mathrm{L} \mathrm{Na}$-acetate, $100 \mathrm{mmol} / \mathrm{L}$ Tris- $\mathrm{HCl}$, $\mathrm{pH}$ 8.5) for $1 \mathrm{~h}$ at $4-8{ }^{\circ} \mathrm{C}$, followed by $1 \mathrm{~h}$ of electrophoresis using the same buffer composition at $4-8{ }^{\circ} \mathrm{C}, 0.5 \mathrm{~V} / \mathrm{cm}$ and $10-11 \mathrm{~mA}$. Then, the microgels were neutralized with three changes of $0.4 \mathrm{~mol} / \mathrm{L}$ Tris-HCl buffer ( $\mathrm{pH} 7.5)$ at $5 \mathrm{~min}$ intervals and stained with ethidium bromide $(20 \mu \mathrm{g} / \mathrm{mL})$. The level of DNA damage in individual cells was assessed with an image analysis system (Comet Assay IVTM, Instem-Perceptive Instruments Ltd., Suffolk, Halstead, UK) using an epifluorescence microscope (Olympus BX50, Tokyo, Japan) under 200× magnification. A total of 100 comets per rat were scored. Tail length (TL) and tail intensity (TI) (i.e., DNA \% in tail) were chosen as indicators of DNA damage.

\subsection{Statistical Analysis}

LDH activity, albumin, cytokines, chemokines and comet assay tail length and tail intensity were analyzed using general linear models. The LDH activity model had activity as a dependent variable and group (with levels: control (CTL), sterigmatocystin (STC), 5-metoxysterigamotcystin (5-M-STC) and the combination of sterigamtocystin and 5-metoxysterigmatocystin (STC + 5-M-STC)) as an independent variable. The albumin model had the $\log _{10}$-transformed concentration as a dependent variable and group as an independent variable. Cytokines (TNF- $\alpha$ and IL-6) and the chemokine MIP-1 $\alpha$ had the $\log _{10}$-transformed concentration as a dependent variable, group as a fixed factor and rat identifier as a random factor (to account for dependencies between repeated measures) [39]. For the dependent variable, tail intensity and tail length (for both comet assays) models had $\log _{10}$-transformed values. Since some values of tail intensity were equal to zero, $1 \%$ was added to all tail intensity values prior to transformation. Within independent variables, group was defined as a fixed factor, and rat identifier and slide identifier (nested within rat identifier) were random factors.

For all analyzed variables, after fitting models, a $t$-test as a post hoc test was applied on the group factor to assess the differences between each level and control, along with comparisons of the combination of mycotoxins with each mycotoxin [40]. The false discovery rate was controlled with the Bonferroni method. The level of statistical significance was set to 0.05 . The results were plotted using ggplot2 package version 3.3.0 (5 March 2020) [41]. All statistical analyses were performed in $R$ software version 3.6.3 (29 February 2020) for statistical computing [42].

Author Contributions: Conceptualization, M.Š.K.; methodology, D.J., D.R., N.K. and V.M.; formal analysis, D.K., I.Ć. and D.J.; investigation, D.J., I.Ć., D.K., D.R. and M.Š.K.; writing—original draft preparation, M.Š.K.; writing—review and editing, D.J., D.R., D.K., N.K. and M.P.; visualization, D.K.; supervision, M.Š.K. All authors have read and agreed to the published version of the manuscript.

Funding: This research was funded by the Croatian Science Foundation, grant number IP-09-2014-5982.

Acknowledgments: The authors want to thank Makso Herman for English language editing.

Conflicts of Interest: The authors declare no conflict of interest.

\section{References}

1. Bloom, E.; Bal, K.; Nyman, E.; Must, A.; Larsson, L. Mass spectrometry-based strategy for direct detection and quantification of some mycotoxins produced by Stachybotrys and Aspergillus spp. in indoor environments. Appl. Env. Microbiol. 2007, 73, 4211-4217. [CrossRef]

2. Engelhart, S.; Loock, A.; Skutlarek, D.; Sagunski, H.; Lommel, A.; Färber, H.; Exner, M. Occurrence of toxigenic Aspergillus versicolor isolates and sterigmatocystin in carpet dust from damp indoor environments. Appl. Env. Microbiol. 2002, 68, 3886-3890. [CrossRef]

3. Täubel, M.; Hyvärinen, A. Occurrence of mycotoxins in indoor environments. In Environmental Mycology in Public Health: Fungi and Mycotoxins Risk Assessment and Management; Viegas, C., Pinheiro, A.C., Sabino, R., Viegas, S., Brandão, J., Veríssimo, C., Eds.; Elsevier: Amsterdam, The Netherlands, 2016; pp. 299-323, ISBN 9780124114715. 
4. Houbraken, J.; Kocsubé, S.; Visagie, C.M.; Yilmaz, N.; Wang, X.-C.; Meijer, M.; Kraak, B.; Hubka, V.; Bensch, K.; Samson, R.; et al. Classification of Aspergillus, Penicillium, Talaromyces and related genera (Eurotiales): An overview of families, genera, subgenera, sections, series and species. Stud. Mycol. 2020, 95, 5-169. [CrossRef] [PubMed]

5. Jakšić Despot, D.; Kocsubé, S.; Bencsik, O.; Kecskeméti, A.; Szekeres, A.; Vágvölgyi, C.; Varga, J.; Šegvić Klarić, M. New sterigmatocystin-producing species of Aspergillus section Versicolores from indoor air in Croatia. Mycol. Prog. 2016, 16, 63-72. [CrossRef]

6. Š́egvić Klarić, M.; Jakšić, D.; Kocsubé, S.; Kifer, D.; Sulyok, M.; Jelić, D.; Šarkanj, B. Post-flood indoor occurrence of toxigenic Aspergilli from the Versicolores clade: Is it dangerous? In Proceedings of the Romanian Journal of Laboratory Medicine, Timisoara, Romania, 13-15 September 2018; Volume 26, pp. S12-S13.

7. Jakšić Despot, D.; Kocsubé, S.; Bencsik, O.; Kecskeméti, A.; Szekeres, A.; Vágvölgyi, C.; Varga, J.; Šegvić Klarić, M. Species diversity and cytotoxic potency of airborne sterigmatocystin-producing Aspergilli from the section Versicolores. Sci. Total Environ. 2016, 562, 296-304. [CrossRef]

8. Cabaret, O.; Puel, O.; Botterel, F.; Delaforge, M.; Bretagne, S. Metabolic detoxification pathways for 5-methoxy-sterigmatocystin in primary tracheal epithelial cells. Xenobiotica 2013, 44, 1-9. [CrossRef]

9. EFSA. Scientific Opinion on the risk for public and animal health related to the presence of sterigmatocystin in food and feed. EFSA J. 2013, 11, 1-81.

10. IARC. Sterigmatocystin. Iarc Monogr. Eval. Carcinog. Risk Chem. Man 1976, 10, 245-251.

11. Cui, J.; Wang, J.; Huang, S.; Jiang, X.; Li, Y.; Wu, W.; Zhang, X. Sterigmatocystin induced apoptosis in human pulmonary cells in vitro. Exp. Toxicol. Pathol. 2017, 69, 695-699. [CrossRef]

12. Nieto, C.H.D.; Granero, A.M.; Zon, M.A.; Fernández, H. Sterigmatocystin: A mycotoxin to be seriously considered. Food Chem. Toxicol. 2018, 118, 460-470. [CrossRef]

13. Wang, J.; Huang, S.; Xing, L.; Shen, H.; Yan, X.; Wang, J.; Zhang, X. Role of hMLH1 in sterigmatocystin-induced G2 phase arrest in human esophageal epithelial Het-1A cells in vitro. Toxicol. Lett. 2013, 217, 226-234. [CrossRef] [PubMed]

14. Miller, J.; Sun, M.; Gilyan, A.; Roy, J.; Rand, T. Inflammation-associated gene transcription and expression in mouse lungs induced by low molecular weight compounds from fungi from the built environment. Chem. Interact. 2010, 183, 113-124. [CrossRef]

15. Mori, H.; Sugie, S.; Yoshimi, N.; Kitamura, J.; Niwa, M.; Hamasaki, T.; Kawai, K. Genotoxic effects of a variety of sterigmatocystin-related compounds in the hepatocyte/DNA-repair test and the Salmonella microsome assay. Mutat. Res. Lett. 1986, 173, 217-222. [CrossRef]

16. Jakšić, D.; Puel, O.; Canlet, C.; Kopjar, N.; Kosalec, I.; Šegvić Klarić, M. Cytotoxicity and genotoxicity of versicolorins and 5-methoxysterigmatocystin in A549 cells. Arch. Toxicol. 2012, 86, 1583-1591. [CrossRef]

17. Kifer, D.; Jakšić, D.; Šegvić Klarić, M. Assessing the effect of mycotoxin combinations: Which mathematical model is (the most) appropriate? Toxins 2020, 12, 153. [CrossRef]

18. Cabaret, O.; Puel, O.; Botterel, F.; Pean, M.; Khoufache, K.; Costa, J.-M.; Delaforge, M.; Bretagne, S. Metabolic detoxication pathways for sterigmatocystin in primary tracheal epithelial cells. Chem. Res. Toxicol. 2010, 23, 1673-1681. [CrossRef]

19. Micheluz, A.; Sulyok, M.; Manente, S.; Krska, R.; Varese, G.; Ravagnan, G. Fungal secondary metabolite analysis applied to Cultural Heritage: The case of a contaminated library in Venice. World Mycotox. J. 2016, 9 , 397-407. [CrossRef]

20. Tsuda, A.; Henry, F.S.; Butler, J.P. Particle transport and deposition: Basic physics of particle kinetics. Compreh. Physiol. 2013, 3, 1437-1471. [CrossRef]

21. Morawska, L.; Afshari, A.; Bae, G.N.; Buonanno, G.; Chao, C.Y.H.; Hänninen, O.; Hofmann, W.; Isaxon, C.; Jayaratne, E.R.; Pasanen, P.; et al. Indoor aerosols: From personal exposure to risk assessment. Indoor Air 2013, 23, 462-487. [CrossRef]

22. Gravesen, S.; Nielsen, P.A.; Iversen, R.; Nielsen, K.F. Microfungal contamination of damp buildings-examples of risk constructions and risk materials. Environ. Health Perspect. 1999, 107, 505-508. [CrossRef]

23. Nielsen, K.F.; Gravesen, S.; Nielsen, P.A.; Andersen, B.; Thrane, U.; Frisvad, J.C. Production of mycotoxins on artificially and naturally infested building materials. Mycopathologia 1999, 145, 43-56. [CrossRef] [PubMed]

24. Rašić, D.; Jakšić, D.; Hulina Tomašković, A.; Kifer, D.; Kopjar, N.; Rumora, L.; Želježić, D.; Peraica, M.; Šegvić Klarić, M. Sterigmatocystin moderately induces oxidative stress in male Wistar rats after short-term oral treatment. Mycotox. Res. 2019, 36, 181-191. [CrossRef] 
25. Liu, L.; Liu, R.; Basnet, B.B.; Bao, L.; Han, J.; Wang, L.; Liu, H. New phenolic bisabolane sesquiterpenoid derivatives with cytotoxicity from Aspergillus tennesseensis. J. Antibiot. 2018, 71, 538-542. [CrossRef]

26. Turner, M.D.; Nedjai, B.; Hurst, T.; Pennington, D.J. Cytokines and chemokines: At the crossroads of cell signalling and inflammatory disease. Biochim. Biophys. Acta Mol. Cell Res. 2014, 1843, 2563-2582.

27. Suganuma, M.; Okabe, S.; Marino, M.W.; Sakai, A.; Sueoka, E.; Fujiki, H. Essential role of tumor necrosis factor $\alpha($ TNF- $\alpha)$ in tumor promotion as revealed by TNF- $\alpha$-deficient mice. Cancer Res. 1999, 59, 4516-4518.

28. Duque, G.A.; Descoteaux, A. Macrophage Cytokines: Involvement in immunity and infectious diseases. Front. Immunol. 2014, 5, 491. [CrossRef]

29. Preedy, V.R.; Patel, V.B. (Eds.) General Methods in Biomarker Research and Their Applications; Springer: Berlin, Germany, 2015.

30. Zhang, X.H.; Yao, Z.G.; Wang, J.; Xing, L.X.; Xia, Y. Effects of sterigmatocystin on TNF-? IL-6 and IL-12 expression in murine peripheral blood mononuclear cells and peritoneal macrophages in vivo. Mol. Med. Rep. 2012, 5, 1318-1322. [CrossRef]

31. Korkalainen, M.; Täubel, M.; Naarala, J.; Kirjavainen, P.; Koistinen, A.; Hyvärinen, A.; Komulainen, H.; Viluksela, M. Synergistic proinflammatory interactions of microbial toxins and structural components characteristic to moisture-damaged buildings. Indoor Air 2016, 27, 13-23. [CrossRef]

32. Collins, A.R.; Oscoz, A.A.; Brunborg, G.; Gaivão, I.; Giovannelli, L.; Kruszewski, M.; Smith, C.C.; Štětina, R. The comet assay: Topical issues. Mutagenesis 2008, 23, 143-151. [CrossRef]

33. Collins, A.R. The Comet Assay for DNA Damage and Repair: Principles, Applications, and Limitations. Mol. Biotechnol. 2004, 26, 249-261. [CrossRef]

34. Jakšić, D.; Šegvić Klarić, M.; Crnolatac, I.; Vujičić, N.; Šijaković Smrečki, V.; Górecki, M.; Pescitelli, G.; Piantanida, I. Unique aggregation of sterigmatocystin in water yields strong and specific circular dichroism response allowing highly sensitive and selective monitoring of bio-relevant interactions. Mar. Drugs 2019, 17, 629. [CrossRef]

35. Huang, S.; Wang, J.; Xing, L.; Shen, H.; Yan, X.; Wang, J.; Zhang, X. Impairment of cell cycle progression by sterigmatocystin in human pulmonary cells in vitro. Food Chem. Toxicol. 2014, 66, 89-95. [CrossRef] [PubMed]

36. Mihaljević, Z.; Ternjej, I.; Stanković, I.; Ivković, M.; Zelježić, D.; Mladinić, M.; Kopjar, N. Assessment of genotoxic potency of sulfate-rich surface waters on medicinal leech and human leukocytes using different versions of the Comet assay. Ecotoxicol. Env. Saf. 2011, 74, 1416-1426. [CrossRef]

37. Wojewódzka, M.; Gradzka, I.; Buraczewska, I. Modified neutral comet assay for human lymphocytes. Nukleonika 2002, 47, 1-5.

38. Singh, N.P.; McCoy, M.T.; Tice, R.R.; Schneider, E.L. A simple technique for quantitation of low levels of DNA damage in individual cells. Exp. Cell Res. 1988, 175, 184-191. [CrossRef] [PubMed]

39. Bates, D.; Mächler, M.; Bolker, B.; Walker, S. Fitting Linear Mixed-Effects Models Using lme4. J. Stat. Softw. 2015, 67.

40. Lenth, R. Emmeans: Estimated Marginal Means, aka Least-Squares Means. 2019. Available online: https: //github.com/rvlenth/emmeans (accessed on 22 November 2020).

41. Wickham, H. ggplot2: Elegant Graphics for Data Analysis; Springer: New York, NY, USA, 2016; ISBN 978-3-319-24277-4.

42. R Core Team. R: A Language and Environment for Statistical Computing; R Foundation for Statistical Computing: Vienna, Austria, 2020.

Publisher's Note: MDPI stays neutral with regard to jurisdictional claims in published maps and institutional affiliations.

(C) 2020 by the authors. Licensee MDPI, Basel, Switzerland. This article is an open access article distributed under the terms and conditions of the Creative Commons Attribution (CC BY) license (http://creativecommons.org/licenses/by/4.0/). 